\title{
Dos espaços de jogo aos mundos jogáveis
}

\section{Olli Tapio Leino}

Doutor; City University of Hong Kong, Hong Kong

otleino@cityu.edu.hk

Tradução: Ivan Mussa

Universidade Federal do Rio Grande do Norte, Natal, RN, Brasil

ivanmussa@gmail.com

Revisão de tradução: Roger Seula

Universidade Federal do Rio Grande do Sul, Porto Alegre, RS, Brasil

rogerseula@gmail.com

\section{Resumo}

Este artigo examina criticamente os fundamentos fenomenológicos daquilo que podemos chamar de "paradigma da espacialidade" no estudo dos videogames - o projeto de se utilizar metáforas e terminologias espaciais para compreender a atividade de jogo. Apoiando-me na tradição (pós)fenomenológica, argumento que, embora essa terminologia seja útil para projetos analíticos que busquem elucidar a estrutura e forma do artefato de jogo, bem como os processos que facilitam, noções espaciais não necessariamente se adequam ao aspecto de primeira-pessoa que constitui a experiência de se jogar um videogame - especialmente nos casos de jogos que não se sustentam em locomoção e propriocepção simuladas em espaços tridimensionais. Além disso, debato que as diferenças entre jogos para um jogador e jogos multiplayer - ou seja, que jogos para um jogador podem ser descritos, usando o enquadramento de relações de intencionalidade de Ihde, como situados em "relações de alteridade", e jogos multiplayer em "relações de mediação" complicam ainda mais a questão da espacialidade nos videogames. Dadas essas observações, sugiro que, se noções espaciais parecem problemáticas para a descrição da experiência em primeira-pessoa de se jogar videogames para um jogador, a noção de 'mundo de jogo' parece mais precisa para designar aquilo com o que os jogadores se envolvem.

\section{Palavras-chave}

Espacialidade. Mundo do Jogo. Experiência de Jogo. 


\section{Introdução}

A espacialidade é por vezes entendida como um dos principais paradigmas através dos quais as novas mídias, em geral, poderiam ser explicadas (MANOVICH, 2012). Sob essa perspectiva, não é surpreendente que uma série de autores (FRIEDMAN, 1999; AARSETH, 2000; JENKINS, 2004; CALLEJA, 2007; GÜNZEL, 2008) tenham abordado os jogos digitais, também, por meio de metáforas espaciais. Foi até mesmo sugerido que enfatizar a espacialidade ao debater sobre jogos digitais pode se configurar como um modo de reconciliação entre duas perspectivas distintas, focadas em jogabilidade e narração (Cf. GÜNZEL 2008). A questão a ser indagada neste artigo, da perspectiva da filosofia da tecnologia (pós-)fenomenológica, é se a viabilidade de uso de terminologias espaciais em análises estende-se ao discurso sobre a experiência vivida de se jogar jogos digitais.

Embora metáforas espaciais pareçam comprovar sua utilidade em projetos analíticos sobre os "textos" dos jogos digitais, essa funcionalidade não se evidencia em propostas que busquem compreender os jogos de uma perspectiva em primeira pessoa ${ }^{1}$, tal qual revelamse no 'processo de jogo' (LEINO, 2009; BAYLISS, 2010; PODLESCHNY, 2012). Em outras palavras, interesso-me em investigar se terminologias espaciais são compatíveis com a experiência vivida de se jogar jogos digitas. Tal questão torna-se relevante especialmente em casos nos quais o jogador está interagindo com artefatos jogáveis incapazes de serem descritos satisfatoriamente tal como produtores de experiências de "simulação de locomoção" em espaços bi ou tridimensionais. Em se tratando de gêneros, essa descrição parece sobrepor-se a definições coloquiais dos gêneros 'puzzle', 'estratégia', 'simulação' e 'tycoon'2.

O leitor pode se perguntar o porquê de eu ter escolhido esses tipos de jogos, ao invés de ambientes 3D, como exemplos pragmáticos a partir dos quais poderia analisar a experiência do espaço em jogos individuais. Aqueles que subscrevem à hipótese de que existe uma categoria de coisas que podemos chamar de "jogos individuais" talvez enxerguem, nos meus exemplos, prismas através dos quais uma nova luz seria lançada sobre outros casos mais convencionais, que, supostamente, se utilizam da ideia 'espaço' tal como ela se apresenta na experiência corporificada - elucidando, também, o papel dessa ideia na

\footnotetext{
${ }^{1}$ Nota do tradutor: Aqui, a ideia de "primeira pessoa" descreve a experiência individual de se envolver com um jogo para um único jogador, e não deve ser confundida com a propriedade dos jogos em "primeira pessoa", nos quais a perspectiva do jogador coincide com o olhar do avatar, como na câmera subjetiva cinematográfica.

${ }^{2}$ Nota do tradutor: Jogos Tycoon são um subconjunto dos jogos de simulação e, por vezes, referidos pela denominação mais geral.
} 
experiência de jogo solitário em geral. Aqueles que não subscrevem à existência de uma categoria referente a "jogos individuais" estão convidados a encarar a análise deste artigo como um ensaio sobre o papel do espaço na experiência de se jogar videogame do gênero "simulação" ou "tycoon".

A afirmação sobre a utilidade das terminologias espaciais na análise de jogos digitais é facilmente fundamentada por observações empíricas. Consideremos, por exemplo, Ferrovias! (2006, conhecido como Railroads!), em que o jogador contempla a paisagem de uma perspectiva aérea móvel com zoom regulável, podendo distribuir estradas ao longo da paisagem - levando em conta a inclinação de montanhas e curvas, bem como custos de construção de pontes e túneis - com o objetivo de designar rotas de transporte de cargas entre cidades, almejando a otimização de lucro. 0 ato de jogar Railroads!, incluindo detalhes como desafios, sucesso e dificuldade, podem ser descritos de forma significativa por meio de terminologias espaciais. Por exemplo: uma distância mais extensa entre uma mina de carvão e uma cidade resulta no aumento dos custos de fixação de pistas; altos níveis de elevação de montanhas ou da inclinação de uma curva resultam em trens mais lentos. Custos e atrasos na entrega acarretam em uma potencial queda dos lucros, que subsequentemente leva ao aumento da dificuldade. Baseando-nos nessas observações, podemos concluir que Railroads!, como muitos (se não todos) jogos digitais, pode ser descrito como um jogo sobre espaço. A seguir, examinaremos se essa observação justifica o uso de terminologias ligadas ao espaço tal qual aquele em que existimos, e até que ponto esse uso se sustentaria em uma análise do jogo enquanto jogado.

\section{0 ‘espaço’ do jogo e a existência}

Abordemos a relação entre terminologias espaciais e existência espacial a partir de Merleau-Ponty (1999, p. 122), de acordo com quem o meu "corpo é o pivô do mundo" e "o termo não percebido no centro do mundo para o qual todos os objetos voltam a sua face". Minha experiência espacial é caracterizada pela percepção do que me rodeia, sob os termos das dimensões e distâncias entre meu corpo e o meu ambiente - quais objetos estão ao meu alcance e quais exigem que eu me levante para alcançá-los e assim por diante. Gallagher e Zahavi (2008, p. 141-144) contextualizam a afirmação de Merleau-Ponty ao delinear três "enquadramentos de referência espacial". 0 "enquadramento proprioceptivo" se refere à minha autoconsciência corporal. É 'de acordo' com tal enquadramento que sei a localização 
de meus braços e pernas sem ponderá-la deliberadamente. 0 enquadramento proprioceptivo é, também, um sine qua non corporal para o "enquadramento egocêntrico", no qual meu corpo é o "ponto-zero experiencial" e "o 'aqui' indicial relativo ao qual qualquer objeto aparente se orienta" (GALLAGHER; ZAHAVI 2008, p. 142). O terceiro, o enquadramento "aleocêntrico", refere-se à concepção pura de espaço 'de acordo' com o qual "não interessa onde você esteja, em Copenhague, Roma ou Nova York; Copenhague sempre está ao norte de Roma." (GALLAGHER; ZAHAVI 2008, p. 141). Assim como em MerleauPonty e Gallagher \& Zahavi, uma observação semelhante é feita por Sartre (2007, p. 66), que sugere que:

A única localização concreta que pode revelar-se a mim é a extensão absoluta, ou seja, justamente aquela que é definida por meu lugar considerado como centro, e para o qual as distâncias são calculadas absolutamente entre o objeto e eu, sem reciprocidade. E a única extensão absoluta é aquela que se desdobra a partir de um lugar que eu sou absolutamente. (SARTRE, 2007, p. 66)

Por reciprocidade, Sartre (2003, p. 512) refere-se às interrelações entre figuras no espaço, constituindo o que ele chama de espaço "geométrico", o que parece corresponder ao modo como Gallagher e Zahavi (2008, p. 141) descrevem o espaço aleocêntrico. Baseados nas concepções de Meleau-Ponty (1999, p. 122), Gallagher e Zahavi (2008, p. 141-144) e Sartre (2007), podemos concluir que qualquer aproximação à ideia de 'existência no espaço' depende do corpo como ponto de vista que se lança ao mundo. Abordar o espaço de jogo comparando-o ao espaço real em que existimos envolve levar em conta os enquadramentos de referência proprioceptivos e egocêntricos em relação ao 'espaço de jogo': em outros termos, deve-se localizar o 'aqui' indicial na descrição, assim como apontar qual seria o fundamento da experiência, se não a propriocepção (Cf. GALLAGHER e ZAHAVI, 2008, p. 141). Como não possuímos corpos que constituam pontos de vista proprioceptivos no interior do espaço dos jogos digitais da mesma maneira que o temos no mundo real, essa linha de argumentação demandaria que introduzíssemos um atalho que desse conta tanto da falta de um corpo "dentro" do jogo quanto de um 'aqui' indicial interno ao espaço do jogo. Tentemos estabelecer esse atalho com Klevjer (2006) e Aarseth (2000). Por um lado, Klevjer (2006) aplica a perspectiva presencial 'dentro' de jogos que utilizam um avatar. Em suas análises, o avatar assume o papel de um 'corpo vicário' por meio do qual o jogador percebe o 
mundo de jogo. Seguindo Klevjer ${ }^{3}$, podemos considerar o avatar como 'o pivô do mundo de jogo', em consonância com Merleau-Ponty. Por outro lado, Aarseth observa que os videogames "são constituídos de signos e são, portanto, dependentes de antemão de nossa experiência corpórea dentro e fora do espaço real para que possam ser 'alucinadas' enquanto espaço" (AARSETH, 2000, p. 162).

Ao conectar as peças de Aarseth (2000) e Klevjer (2006), o resultado é um atalho para a falta do corpo: a proposta de que, enquanto jogadores, observaríamos os signos da tela e, com base no que sabemos sobre locomoção e propriocepção no espaço real, "alucinaríamos" nossa interconexão com os signos, incluindo aqueles constituindo o avatar, tal qual uma simulação da locomoção e da propriocepção. Essa descrição parece funcionar com um jogo narrativo como no caso de Half-Life 2 (2004). Dotado de locomoção representada em três dimensões, narrativa e personagens convincentes e de fácil identificação, o jogo me convida a "imersão" (CALLEJA, 2007) em diversos níveis. 0 jogo convida a imaginar a mim mesmo como Gordon Freeman e a agir como Gordon Freeman - não apenas no que tange às reviravoltas da trama, mas também no que se refere ao meu apoderamento das capacidades locomotivas de Gordon Freeman. No caso de jogos como Half-Life 2, talvez possamos discernir semelhanças suficientes entre a forma com que operamos no espaço real e o modo como operamos no espaço do jogo (por exemplo, em ambos os casos é preciso mover nosso ponto de vista para agarrar ou desviar de algo), o que justificaria equacionar o espaço de jogo ao espaço em que existimos, e, introduzindo a interface da "locomoção alucinada", poderíamos fazer uso de teorias do espaço real para explicar o 'espaço' de jogo. Talvez possamos considerar Half-Life 2 como um caso paradigmático da existência 'alucinada' no espaço jogável de Aarseth e Klevjer.

Examinemos o modo como a descrição da existência 'alucinada' se aplica à experiência de se jogar Railroads!. Embora o jogo também sugira, ao menos até certo ponto, um enquadramento narrativo dentro do qual escolhas e ações poderiam ser explicadas - por exemplo, o jogador pode nomear sua firma ferroviária, e nas telas de carregamento (loading) são mostradas imagens de industrialistas e magnatas ferroviários famosos, com os quais o jogador supostamente possa se identificar -, parece que o entendimento das ações e escolhas nesses jogos requerem menos investimento intelectual em seus aspectos dramáticos, se comparados, por exemplo, a RPGs com perspectiva em primeira pessoa. Um

\footnotetext{
30 simples uso da noção de "avatar" não faz jus às análises de Klevjer (2006), nas quais as tarefas e funções do avatar são rearticuladas com conceitos mais detalhados. Entretanto, a rápida menção aponta para os tipos de medidas que seriam necessárias se optássemos por nos ater à noção de um espaço do mundo do jogo no qual podemos existir.
} 
dos indícios disso em Railroads! é a ausência de 'protagonistas' (no sentido narrativo do jogo) e de NPCs ${ }^{4}$ antropormóficos: eu estou construindo ferrovias e minhas vias férreas foram bloqueadas pela inteligência artificial adversária. Posso me mover em uma perspectiva que remete à de um deus, ampliando e reduzindo meu foco onipresentemente à vontade, de modo a avistar o expresso "Bucharest Bullet" expelindo fumaça negra enquanto sobe as montanhas Carpathian. Além de meramente observar, posso fazer uma melhoria em um depósito em Varna em um momento e, no próximo instante, fixar uma nova via do outro lado da Europa. Não há nem algo que corresponda a um corpo 'interno' ao jogo nem um enquadramento ficcional que me abrigue como 'corpo virtual', como vemos no exemplo de Half-Life 2. De modo a discursar sobre minha existência 'no espaço' de Railroads! de maneira similar à que falamos da minha existência alucinada em Half-Life 2, precisaríamos deformar tão drasticamente a noção de existência no espaço que ela perderia boa parte de seus poderes descritivos, pois acabaríamos chegando a algo como 'existência onipresente desincorporada'. Parece-me desnecessário, enquanto jogador, 'imaginar', 'alucinar' ou, em suma, conjurar ficções de mim mesmo existindo 'dentro' de Railroads! para me envolver com a dinâmica de seu espaço.

A experiência de me envolver com o 'espaço' de Sid Meier's Railroads! talvez possa ser descrita sem designar qualquer corpo, seja ficcional ou imaginado, como pivô do 'mundo de jogo'. Abandonar a noção de 'existência' nos livraria do dever de demonstrar uma presença objetiva no espaço de jogo, o que nos confrontaria com a evidente falta dessa presença se recorrêssemos à 'ficção' e ao 'faz-de-conta', ideias que não se alinham à experiência pessoal e intuitiva de que as vias férreas de Railroads! são "minhas vias", assim como o texto que aparece agora na tela de meu computador é "meu texto".

Já que qualquer noção de experiência espacial deve ser enraizada em um enquadramento proprioceptivo, e já que não há propriocepção nos jogos digitais (nem em Half-Life 2, nem em Railroads!), não pode haver experiência espacial propriamente dita nos videogames. Na melhor das hipóteses, poderíamos falar de um tipo de 'espaço representado', entendendo que o jogador o constrói por meio da 'alucinação', durante sua experiência. Embora tal abordagem pudesse abrir rotas de investigação convenientes, não há razão para pressupor automaticamente que a relação entre jogador e a representação espacial de um jogo seria equivalente à que possuímos com a espacialidade real - ou seja, a relação caracterizada pela existência.

${ }^{4}$ Non-playable characters, ou personagens não-jogáveis. 
Como jogos digitais fazem coisas estranhas com a temporalidade - como os buracos de minhoca (wormholes) dos salvamentos, carregamentos e cutscenes (Cf. JUUL, 2004), não seria absurdo supor que eles são capazes de alterar a espacialidade de modos igualmente estranhos - como, por exemplo, ao nos envolver em algo que pode remeter a um 'espaço' sem recorrer a um pivô de existência proprioceptiva. Negar a possibilidade de uma experiência de espaço real em Railroads! não nos impede de discutir uma representação espacial no sentido de seu enquadramento aleocêntrico (Cf. GALLAGHER; ZAHAVI, 2008, p. 141). Por exemplo, sem ter que considerar o 'aqui' indicial ou o processo de espacialização e suas origens, podemos comparar distâncias entre cidades e concluir que traçar uma via entre Veneza e Berlim por sobre os Alpes é mais econômico que contornar as montanhas. É o que um jogador bem-sucedido provavelmente faria.

No restante deste artigo, tentarei mostrar de que modo a experiência da significação do espaço em Railroads! pode ser descrita sem reproduzir o modelo no qual o espaço real é significativo para a corporificação dos seres humanos. Dessa exposição, emerge uma diferença importante entre jogos individuais e jogos multijogador.

\section{Dos "espaços simulados" aos "mundos jogáveis"}

Como já foi sugerido, a espacialidade é importante em muitos jogos digitais e, como discutimos previamente, as descrições do 'espaço' de jogo enquanto 'representação' (Cf. AARSETH, 2000; ADAMS, 2003) e como 'navegável' (FRIEDMAN, 1999), entre outras, parecem coerentes. Embora compreensões dos 'espaços' de jogo como 'representáveis', 'navegáveis' ou 'virtuais' sejam válidas, são também um pouco enganosas. Se o 'espaço representado' ou o 'espaço navegável' fossem descrições precisas do papel do espaço em jogos individuais, a espacialidade dos jogos digitais seria facilmente agrupada ao mesmo conjunto de espacialidades da arte interativa, CD-ROMS multimídia, exposições interativas em museus, entre outras. Mesmo que haja semelhanças, intuitivamente sabemos que tal agrupamento não é o mais preciso possível. A seguir, argumentarei que a relação entre o espaço dos jogos individuais e a atividade de jogo solitário não é equivalente àquela entre o recipiente e seu conteúdo, mas sim a um entrelaçamento mais delicado no qual a representação espacial age a serviço de um mecanismo de liberdade e responsabilidade. A implicação dessa dualidade entre liberdade e responsabilidade aparenta ser aquilo que distingue o 'espaço' de jogo do espaço representado. 
Aarseth, Smedstad e Sunnanå postulam uma distinção entre "jogos em ambientes virtuais - ou seja, jogos que se passam em alguma forma de ambiente simuladio" e "jogos puramente abstratos, como Poker e Blackjack" (2003, p. 48). Aarseth sugere que esse rótulo "se adequa a jogos desde Tetris, passando por Drug Wars, até EverQuest", embora exclua "brinquedos computadorizados como Furby, dados e jogos de cartas como Blackjack" (2003, p. 2). Curiosamente, a noção também abrange "jogos de simulação não-computadorizados, tal qual Monopoly e Dungeons \& Dragons". Subliminar à ideia de "jogos em ambientes virtuais" parece haver a ideia de que o espaço de jogo age como recipiente, ou como uma arena, para a realização da atividade. Jogos multijogador, como World of Warcraft (2004) ou League of Legends (2009), permitem que seus jogadores comuniquem-se entre si através de suas ações dentro do jogo, tornando-se presentes uns em relação aos outros por meio de representações exibidas na tela. Nessa linha descritiva, a tecnologia facilita o processo de jogo que acontece entre os jogadores (Cf. WOODS, 2007). A partir dessa elucidação, parece plausível que nos refiramos a jogos multijogador, seguindo Aarseth, Smedstad e Sunnanå, como "jogos em ambientes virtuais".

Ihde (1990, p. 72-107) distingue dois tipos de tecnologias: as que atuam em "relações de mediacão", ou seja, mediam a experiência humana do mundo; e tecnologias que atuam em "relações de alteridade", ou seja, aquelas que são tratadas como 'pseudo-outros', funcionando como um "terminal de experiência" (VERBEEK, 2008, p. 389). Óculos e termômetro mediam experiências, enquanto máquinas bancárias de autoatendimento e brinquedos de parques de diversão atuam como terminais de experiências. Jogos multiplayer permitem que seus jogadores percebam algo sobre o mundo: os outros jogadores e suas ações, que não seriam perceptíveis sem o artefato do jogo. Sob esta ótica, parece plausível descrever o artefato tecnológico do jogo multijogador, ou o "mundo virtual" que apresenta, tal como um ator em uma relação de mediação.

o jogo individuais, em contraste, é um pseudo-outro, um terminal para uma experiência. Interagimos com esses jogos, não através deles. Jogos individuais não permitem que percebamos nada além deles próprios. Se observarmos jogos como Railroads!, parece mais sensato designar que atuam em "relações de alteridade". Deparamo-nos aqui com duas espécies muito distintas de relação humano-tecnologia e agrupá-las sob a mesma categoria apenas devido à referência coloquial de que ambos são "jogos digitais" ou "ambientes virtuais" significaria ignorar a riqueza de detalhes de suas especificidades tecnológicas, inclusive aquelas relacionadas à espacialidade. 0 que distingue os jogos digitais dos 'espaços 
navegáveis', 'ambientes virtuais' e similares parece ser a subordinação da representação espacial, entre outras modalidades de representação, ao gameplay. Tal fato requer um desvio de 'espaços de jogo' para o que podemos chamar de 'mundos jogáveis'. Focarei, em seguida, nesse desvio.

Observemos a relação entre espacialidade e jogabilidade recorrendo a Wark (2007). 0 autor, ao discutir o modo com a espacialidade dos jogos digitais é experimentada, aponta que "o algoritmo consome o que é topográfico e transforma em topológico". A transformação do topográfico em topológico pode ser ilustrada ao nos referirmos ao 'jogo artístico' Proteus (2013), de Ed Key e David Kanaga. Embora a perspectiva espacial em Proteus seja razoavelmente distinta daquela encontrada em Railroads!, esse exemplo permite ilustrar a transformação mencionada previamente. Proteus permite que seu usuário mova um ponto de vista pela paisagem de uma ilha, retratada em gráficos de estilo colorido remetentes aos computadores caseiros da década de 1980. As estações do ano e o ciclo dianoite avançam, e assim que tenham completado seu curso, a visita do usuário à ilha se encerra e o artefato de jogo retorna ao seu menu principal. 0 jogador encontra galinhas, um NPC com um pula-pula e outras criaturas semelhantes. Parece haver uma trilha sonora gerada computacionalmente - que evolui de acordo com as ações do jogador complementado as atrações da obra, que configura um espetáculo audiovisual efetivamente convidativo.

Movimentar a câmera em Proteus é um ato bastante semelhante à movimentação de câmeras em jogos de tiro em primeira pessoa. No entanto, ao contrário desses jogos, nos quais, em geral, detalhes do ambiente podem ser manipulados de diferentes maneiras, não há funções de interação além da 'navegação' pelo espaço representado em Proteus - com exceção de NPCs que fogem quando se deparam com a câmera. Sobreviver à visita à ilha de Proteus não é difícil - não há riscos, o usuário não pode falhar. Nos jogos de tiro, certos locais podem ser mais importantes, mais perigosos ou mais úteis que outros à medida que se tornam relevantes em relação ao projeto de sobrevivência do jogador (Cf. LEINO, 2013). Como sobreviver não é uma questão em Proteus, tais distinções não podem ser designadas sobre seu espaço.

Aarseth (2000, p. 163) sugere que a constituição da representação espacial nos jogos é "uma operação redutiva que leva à uma representação, mas que não é, em si, espacial, e sim simbólica e baseada em regras", onde "as reduções" são empregadas "como meio pelo qual se alcança o objeto do gameplay". Se traçarmos uma ponte desta ideia à de Wark (2007), 
podemos sugerir que a experiência de jogo possibilitada pela representação espacial envolve a redução do topográfico ao topológico. É possível enxergar uma tentativa de criar um "mundo topográfico" dotado de características estéticas muito particulares em Proteus no modo como seu terreno é formado e na aparência de suas texturas - mas a partir de Wark, observa-se que o ambiente representado no jogo permanece "topográfico", já que não há nele qualquer "algoritmo" de acordo com o qual o ambiente seria convertido em "topológico". Proteus convida seu usuário a apreciar sua topografia, ou seu "mundo virtual", em sua totalidade estética, sem a redução característica do ato de jogo.

É claro, nada impede que alguém faça uso do ambiente virtual de Proteus para jogar sejam quais forem os jogos que conceber e, assim, manter mentalmente a redução do topográfico ao topológico. Pode-se, com um cronômetro, jogar uma partida de " $100 \mathrm{~m}$ rasos", mas o software não distinguirá entre as ações do jogador e, portanto, não encorajará um ou outro modo particular de redução do topográfico ao topológico. Uma paisagem habitada por uma árvore, por exemplo, permanece uma representação da árvore, sem tornar-se um nó posicionado em relação a outros nós.

Gallagher e Zahavi (2008, p. 153) afirmam que a "espacialidade do mundo da vida- do mundo no qual vivemos - não é capturada por mensurações geométricas, mas sim estruturada por contextos de uso". Ao nos tornar responsáveis pela liberdade da qual gozamos como jogadores - ou seja, fazendo-nos encarar o risco de não sobrevivermos jogos individuais impõem modos particulares, se não contextos, de uso - os quais podemos abordar como o "gameplay" de um jogo específico. É possível fazer outras coisas também, mas para sobreviver é preciso preencher os requisitos rigidamente codificados no artefato de jogo. Tais requisitos apresentam o 'contexto de uso' que estrutura as formas com as quais lidamos com o 'espaço' de Railroads!. Prosseguimos com alguns exemplos.

Empregados à experiência de jogar Railroads!, a consumação do topográfico e sua transformação em topológico significa que, para ter sucesso como jogador, não precisamos apreender a paisagem nos termos de suas propriedades topográficas (por exemplo, "aquilo é uma cidade, ali há uma montanha”). Ao invés disso, um jogador de sucesso entenderá a paisagem como uma multiplicidade de diferentes modos potenciais de relação entre os possíveis nós que ela contém. Por exemplo: Frankfurt produz carvão, que precisa ser transportado até Trieste. No entanto, há várias rotas potenciais entre os dois locais, cada uma com benefícios e desvantagens. 0 jogador pode escolher entre diferentes tipos de relação entre Trieste e Frankfurt; por exemplo, como prefere lidar com a cordilheira que 
separa as duas cidades. Todas relações potenciais entre Frankfurt e Trieste terão impactos mais ou menos distintos sobre às possibilidades de escolhas de relações futuras entre essas duas e outras cidades por parte do jogador.

Antes que qualquer via seja construída entre as cidades, o jogador precisa decidir se serão trilhos duplos ou simples. Em suma, a trilhos duplos custam o dobro dos simples, mas dá ao jogador mais flexibilidade de planejamento para que trens viagem não apenas entre as duas cidades, mas dando à via capacidade de levar trens por rotas que se estendam além de Frankfurt e Trieste. Rotas curtas são sempre mais econômicas, mas construir um túnel para atravessar uma montanha pode ser bastante caro. A função de distribuir trilhos no jogo segue uma lógica um tanto difusa, talvez em uma tentativa de simplificar a usabilidade de sua interface, quando precisa decidir se constrói viadutos, pontes, túneis ou trilhos convencionais ao ar livre; supostamente baseando-se nas propriedades locais e na direção de ida e volta traçadas pela construção da via.

No entanto, é possível fazer com que o trilho escale as encostas das montanhas, economizando, portanto, os custos de construção dos túneis; porém essa estratégia requer um planejamento cuidadoso, que envolve posicionar as vias em pedaços bem pequenos, ao invés de simplesmente arrastar os trilhos do ponto $A$ ao ponto $B$, deixando que o jogo decida os detalhes. À medida que os trens atingem velocidades maiores em superfícies planas, forçar que ergam suas cargas até o topo de uma montanha provavelmente reduzirá seu ritmo significativamente. Se as minas de Frankfurt puderem produzir mais carvão do que a quantidade máxima que pode ser levada a Trieste pela via mais curta através das montanhas em um determinado período de tempo, essa rota significará margens de lucro inferiores. Traçar a pista por uma passagem natural entre as montanhas seria, em geral, a melhor opção, mas caso a inteligência artificial adversária já tenha construído suas vias no local, a passagem talvez não possa ser usada pelo jogador.

Caso a conexão Frankfurt-Trieste esteja entre os primeiros trilhos a serem construídos em uma determinada sessão de jogo, provavelmente não haverá, no momento, recursos suficientes nem fluxo de lucro disponível ao jogador. Portanto, seu principal objetivo provavelmente seria garantir de início a produção da via dentro das limitações de seu orçamento, ao invés de, por exemplo, otimizar o tempo de viagem com o ciclo de produção da mina de carvão. Desse modo, o jogador pode decidir pela opção menos custosa: conectar Frankfurt e Trieste passando por cima dos Alpes e não por baixo, ziguezagueando entre as descidas e aclives, procurando caminhos por sobre e em volta das montanhas de 
maior inclinação. 0 fundamental aqui é que a "inclinação" com a qual o jogador que está preocupado em economizar não se refere à qualidade "topográfica" de algo inclinado, tal qual a conhecemos na nossa experiência espacial cotidiana (como montanhas íngremes aparentam de verdade ou a sensação de ficar de pé sobre suas inclinações, por exemplo), e sim a uma propriedade específica de certas localizações internas do jogo, de acordo com a qual esse sugerirá um túnel custoso ao invés de uma via mais barata, porém mais lenta. 0 que acontece é que, em relação ao projeto de completar a sua primeira linha de transporte de carvão entre Frankfurt e Trieste, o conceito de "inclinação", que exerce sua significação na vivência e história de seres humanos corporificados, é transformado em "intransponível sem túnel", um conceito que só tem significado para jogadores de Railroads!.

A partir da elucidação acima, parece possível considerar que a representação espacial, assim como muitos outros aspectos de jogos individuais (no caso de Railroads!, por exemplo: o modelo econômico, os sons das locomotivas, as tarefas pré-definidas cujas execuções são recompensadas com pagamentos extras, etc.) é subordinada ao gameplay. Os atributos espaciais das montanhas e cidades de Railroads! se mostram como nós de uma rede que precisa ser gerenciada pelo jogador, para que este não seja expulso dela. Assim, uma descrição mais fiel ao papel do espaço na experiência de se jogar jogos digitais mencionaria a jogabilidade (no sentido de 'espaço jogável') ao invés de 'representação' (no sentido de 'espaço representado'), simulação (no sentido de 'espaço simulado') ou 'virtualidade' (no sentido de 'espaço virtual').

'Espaço jogável' aparenta ser uma denominação mais precisa da função do espaço nos jogos digitais para um jogador do que 'espaço simulado', que também poderia descrever o 'espaço' de instalações interativas e aplicações multimídia. No entanto, não parece estar clara a razão pela qual deveríamos continuar usando metáforas espaciais, a não ser que haja motivações específicas para analisar os jogos digitais nos termos de suas representações espaciais. Em outra oportunidade (LEINO, 2009), sugeri, por meio de um argumento que não reproduzirei aqui, que a luta por sobrevivência que caracteriza a experiência de jogos individuais - ou seja, a "condição do gameplay" - lembra a luta por sobrevivência encarada por humanos no mundo, a "condição humana" (SARTRE, 1943; SARTRE, 2007). Talvez, ao seguir a linha argumentativa exposta por Möring (2013), as metáforas espaciais pudessem ser substituídas pelo que poderia ser abordado como uma metáfora existencial, o que nos permitiria falar sobre 'mundos de jogo', no lugar de 'espaços de jogo'. Nessa terminologia, o 'mundo' não é tido como um recipiente onde atividades ou processos acontecem, nem 
tampouco seria definido por seus aspectos espaciais; ao invés disso, refere-se à natureza do compromisso existencial assumido pelos jogadores em relação ao artefato jogável: 'mundo de jogo' seria o lugar de onde o jogador de um jogo individual corre o risco constante de ser expulso.

\section{Conclusões}

Examinei, nesse artigo, a viabilidade de se usar terminologias espaciais para descrever a experiência de jogar jogos digitais para um jogador. Embora eu tenha reconhecido como viável a análise de jogos por meio de termos ligados à ideia de espaço - bem como a relevância de se usar palavras que descrevem aspectos espaciais em diversos jogos - a investigação sugeriu que a noção de 'espaço de jogo' é problemática quando se quer descrever a experiência de um jogo digital. Isso é especialmente verdadeiro caso consideremos a ideia de Merleau-Ponty do corpo como 'o pivô do mundo' como base para a experiência espacial. Sintetizando Aarseth (2000) com Klevjer (2006), argumentei que, caso designemos essa ideia como fundamento da experiência, falar de 'espaço de jogo' exige que se inclua na análise a 'locomoção e propriocepção alucinadas' como interface conceitual. Esse movimento aparenta ser razoável apenas em referência a um conjunto limitado de jogos individuais, especificamente os 'jogos narrativos', que pedem ao jogador que imagine não só os eventos da trama como reais, mas também que o corpo do avatar pertence a ele.

Ao fazer uso da distinção de Ihde (1990) entre relações humano-tecnologia caracterizadas por mediação e alteridade, sugeri uma importante diferença entre jogos individuais e multijogador. Os primeiros são aqueles que percebemos e com os quais interagimos, enquanto os segundos são aqueles através dos quais percebemos e interagimos. Sendo assim, podemos dizer que os jogos individuais aparecem em relações de alteridade, e jogos multijogador em relações de mediação. Essa observação me impeliu a questionar a validade da ideia de espaço de jogo como um 'recipiente' para a atividade de jogo (Cf. AARSETH; SMEDSTAD; SUNNANÅ, 2003) quando empregada no sentido de descrever o processo de jogo de jogos individuais.

A partir de Aarseth (2000) e Wark (2007), sugeri que o que ocorre em representações espaciais durante este processo não é necessariamente diferente daquilo que acontece em outros tipos de representação; por meio de uma transformação redutiva, elas tornam-se relevantes em relação ao jogador e sua luta para sobreviver à resistência do artefato de jogo. 
Nessa dinâmica, os aspectos que fazem do espaço aquilo que reconhecemos no dia-a-dia de nossa experiência corporificada costumam desaparecer. Portanto, subscrevendo a Möring (2013), sugeri que talvez as metáforas espaciais pudessem ser substituídas por 'metáforas existenciais' e, consequentemente, falar em 'mundos de jogo' ao invés de 'espaços de jogo' resultaria em uma designação mais fiel à experiência vivida individual.

\section{Referências}

AARSETH, E.. Allegories of Space: The Question of Spatiality in Computer Game. In: ESKELINEN, M.; KOSKIMAA, R. (Ed.). Cybertext Yearbook 2000. [s.l]: University Of Jyväskylä, 2000. p. 152-171.

AARSETH, E.. Playing Research: Methodological approaches to game analysis. Fine Art Forum, [s.l], v. 17, n. 8, 2003.

AARSETH, E.; SMEDSTAD, S.; SUNNANA, L.. Multi-Dimensional Typology of Games. In: DIGRA. 2003, [s.l]. Proceedings... . [s.l]: 2003.

ADAMS, E. The Construction of Ludic Space. In: DIGRA. 2003, [s.l]. Proceedings... . [s.l]: 2003.

BAYLISS, P.. Videogames, Interfaces, and the Body: The importance of embodied phenomena to the experience of videogame play. 2010. Tese (Doutorado), School Of Media And Communication, Rmit University, [s.l], 2010.

CALLEJA, G. Digital Games as Designed Experience: Reframing the Concept of Immersion. 2007. Tese (Doutorado), Victoria University of Wellington, [s.l], 2007.

FRIEDMAN, T.. Civilization and Its Discontents: Simulation, Subjectivity, and Space. In: SMITH, G. (Ed.). Discovering discs: Transforming Space and Genre on CD-ROM. New York: NYUP, 1999.

GALLAGHER, S.; ZAHAVI, D. The Phenomenological Mind: An introduction to philosophy of mind and cognitive science. Londres e New York: Routledge, 2008.

GÜNZEL, S.. The Spatial Turn in Computer Game Studies. In: FUTURE AND REALITY OF GAMING, 2008, [s.l]. Proceedings... . [s.l]: 2008.

IHDE, D. Technology and the lifeworld: from garden to earth. [s.l]: Indiana UP, 1990.

JENKINS, H.. Game Design as Narrative Architecture. In: WARDIP-FRUIN, N.; HARRIGAN, P. (Ed.). First Person: New Media as a Story, Performance and Game. Cambridge: Mit Press, 2004.

JUUL, J. Introduction to Game Time. In: WARDIP-FRUIN, N.; HARRIGAN, P. (Ed.). First 
Person: New Media as a Story, Performance and Game. Cambridge: Mit Press, 2004.

KLEVJER, R. What is the Avatar? Fiction and Embodiment in Avatar-Based Singleplayer Computer Games. Tese (Doutorado), University of Bergen, [s.l], 2006.

LEINO, O.. Understanding Games as Played: Sketch for a first-person perspective for computer game analysis. In: THE PHILOSOPHY OF COMPUTER GAMES CONFERENCE, 2009, [s.l]. Proceedings... . [s.l]: 2009.

LEINO, O. Playability and its Absence: A post-ludological critique. In: DiGRA, 2013. Proceedings... . [s.l]: 2013.

MANOVICH, L. The Language of New Media. Cambridge, MA: MIT Press. 2003.

MERLEAU-PONTY, M. Fenomenologia da Percepção. São Paulo: Martins Fontes. 1999.

MÖRING, S. The Marriage: Love at sight, fear at play. In: GAMES, COGNITION \& EMOTION, 12., 2013, Hamburgo. Proceedings... . Hamburgo: 2013.

PODLESCHNY, N. Games for change and transformative learning: An ethnographic case study. Tese (Doutorado), Queensland University of Technology, [s.l], 2012.

SARTRE, Jean-paul. Existentialism Is Humanism. In: KAUFMAN, Walter (Ed.). Existentialism from Dostoyevsky to Sartre.[s.l]: Meridian Publishing Company, 1989.

SARTRE, Jean-Paul 0 Ser e o Nada: ensaio de ontologia fenomenológica. Rio de Janeiro: Vozes, 2007

WARK, M. Gamer Theory. [s.l]: Harvard UP, 2007

VERBEEK, P-P. Cyborg intentionality: Rethinking the phenomenology of human technology relations. Phenom Cogn Sci, n 7. 2008. p. 387-395.

WOODS, S.. Playing with An Other: Ethics in The Magic Circle. In: UNIVERSITY OF JYVÄSKYLÄ. Cybertext Yearbook 2007. [s.l]: University Of Jyväskylä, 2007.

\section{Referências ludográficas}

Valve Corporation, HALF-LIFE 2, PC, 2004.

Riot Games, LEAGUE OF LEGENDS, PC, 2009.

Key, E. and Kanaga, D., PROTEUS, PC, 2013.

Firaxis Games/2K Games, SID MEIER'S RAILROADS!, PC, 2006.

Blizzard/Vivendi, WORLD OF WARCRAFT, PC, 2004. 


\title{
From Game Spaces to Playable Worlds
}

\begin{abstract}
In this paper I will critically examine the phenomenological underpinnings of what we might call the 'spatiality paradigm' in computer game studies - the project of using spatial metaphors and terminology to understand computer game play. Drawing on the (post-)phenomenological tradition, I argue that while this terminology is useful foranalytic projects seeking to shed light on the structure and form of the game artifact and the processes it facilitates, spatial notions do not necessarily resonate with the first-person experience of computer game play, especially in cases of playing games of genres which do not rely on simulated locomotion and proprioception in threedimensionally modeled space. Furthermore, I argue that the differences between single-player and multi-player games namely that single-player games can be described, using Ihde's framework of intentionality relations, as situating in 'alterity relations' and multi-player games in 'relations of mediation' further complicate the issue of spatiality in computer games. Given these observations, I suggest that whereas the spatial notions appear problematic for the purpose of first-person description of the experience of playing single-player computer games, the notion of 'game world' seems more accurate a description of that with which the players are engaged with.
\end{abstract}

\section{Key-words}

Spatiality. Game World. Game Experience. 